THE REPORT of the work of $\mathrm{Dr}$ J. W. King and his colleagues at the Appleton Laboratory (252, 2; 1974) recalls articles contributed to Nature almost a century ago by William Stanley Jevons, economist and statistician, in which he sought to evidence the relation between sunspots and commercial crises $(19,33 ; 1878$ and 19, 588; 1879).

Jevons's early education was in mathematics, chemistry and botany. $\mathrm{He}$ later developed an interest in, and wrote widely on, meteorology. This scientific training influenced his approach to the study of economics. In Letters and Journal of W. Stanley Jevons, edited by his wife (Macmillan, London, 1886) we read:

'He published in Waugh's Australian Almanac for 1859, "Some Data concerning the Climate of Australia and New Zealand", a paper over fifty pages in length, which is best described by his closing words: "My object has been to present in an available form such accurate numerical data as are attainable, and secondly, to group together general information as to the winds, rains, rivers, floods, the geographical features of the country, and the meteorological circumstances of this part of the globe, so as to show what remarkable problems have to be solved, and what interesting connections of cause and effect may ultimately be traced and proved.",

The significance of his method was that, translated into the context of 'political economy', it represented a new approach to the investigation of economic phenomena. In a paper read to the meeting of the British Association at Cambridge in 1862, "On the Study of Periodic Commercial Fluctuations, with five diagrams", Jevons wrote:

"It seems necessary, then, that all commercial fluctuations should be investigated according to the same scientific methods with which we are familiar in other complicated sciences, such especially as meteorology and terrestrial magnetism."

In 1862 , when this was written, Jevons was concerned with seasonal changes and not with the longer swings of the trade cycle; and his interest in meteorology had not led him to the theory of solar variation to explain these larger swings. His famous conclusions on the underlying causes of the trade cycle were advanced in two papers presented to the British Association in 1875 and 1878.

The fate of the first paper, "The Solar Period and the Price of Corn" is recounted in J. M. Keynes's Essays in Biography (Mercury Books, London, 1961):

'Thorold Rogers' "History of Agriculture and Prices in England", which began to appear in 1866, provided Jevons with material for analysing wheat prices over a long period. The commercial crises in his own lifetime had occurred at intervals of ten or eleven years: 1825, 1836-39, 1847, 1857,1866 . Might there not be a connection between these things? "I am aware," Jevons concluded, "that speculations of this kind may seem somewhat far-fetched and finely-wrought; but financial collapses have recurred with such approach to regularity in the last fifty years, that either this or some other explanation is needed." Nevertheless he soon repented of publishing

\section{Sunspots and the business cycle}

$J$. R. Sparkes, lecturer in economics at the University of Bradford, looks at the work of W.S. Jevons (below), who tried to relate sunspot activity and commercial crises a hundred years ago.

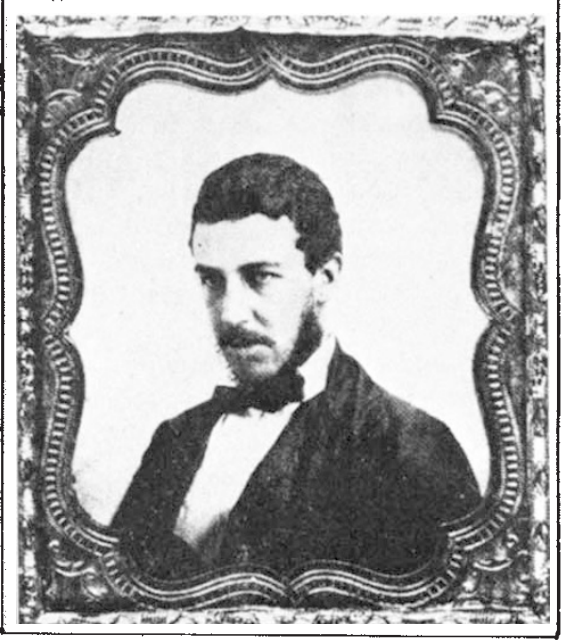

what was no better than a bright idea. "Subsequent enquiry convinced me that my figures would not support the conclusion I derived from them, and I withdrew the paper from publication".'

But Jevons still did not regard the enquiry as worthless and was encouraged to discover, after withdrawing his paper, that Sir William Herschel had tried as early as 1801, although with negative results, to explain the variation in the price of corn by the decennial variation of sunspots. Thus by 1877 he was working at the subject again and was more convinced than ever that there was some connection between sunspots and the price of corn. In a leitter to Professor J. d'Aulnis de Bourouill in February 1878 he wrote, concerning the years when there were commercial crises, "The periodi- city is remarkable, and the average length of the period is somewhere about 10.3 years, so nearly the same as the sunspot period that there can hardly be a doubt about the connection of cause and effect."

Jevons's ideas were spelt out in a second paper to the British Association, "The Periodicity of Commercial Crises and its Physical Explanation", and the first of two articles contributed to Nature. Although still concerned about the evidence on which his theory of crises was based, he had great confidence in its substantial truth.

Keynes, in his essay, listed the new discoveries which were his excuse for returning to his theory:

(1) He had succeeded in carrying back the history of commercial crises at ten or eleven-year intervals almost to the beginning of the eighteenth century.

(2) He was now advised by his astronomical friends that the solar period was not 11.1 years, as he had previously supposed, but 10.45 years, which fitted his series of commercial crises much better.

(3) He now abandoned European harvests, the price statistics for which yielded negative results, as the intermediary through which sunspots affected business, in favour of Indian harvests, which, he argued, transmitted prosperity to Europe through the greater margin of purchasing power available to the Indian peasant for buying imported goods.

But apart from the coincidence of the periodicity of the commercial crises and the solar period, the causal link was never much stronger than a personal conviction that the decennial crises depended on meteorological variations of similar periodicity. His 1875 evidence, which depended on European harvests, was overturned in 1878 in favour of fluctuations in foreign trade resulting from cyclical crop changes in India and elsewhere. But even then the timing of the relationship was such as almost to suggest that the effect preceded its cause.

Later empirical work has largely discredited the theory that there is a link between business cycles and a 10 to 11 year cycle in sunspot activity. Business cycles have recurred at shorter intervals than 10 or 11 years, and in spite of ingenious interpretations of harvest statistics over the years, it is now generally agreed that such an explanation could never completely account for the business cycle. Keynes's assessment is summed up as follows: "Jevons's notion, that meteorological phenomena play a part in harvest fluctuations and that harvest fluctuations play a part (though more important formerly than today) in the trade cycle, is not to be lightly dismissed." 